\title{
Mechanism of Gliotoxin Action and Factors Mediating Gliotoxin Sensitivity
}

\author{
By RICHARD W. JONES* AND JOSEPH G. HANCOCK \\ Department of Plant Pathology, 147 Hilgard Hall, University of California, \\ Berkeley, CA 94720, USA
}

(Received 16 December 1987; revised 4 March 1988)

\begin{abstract}
Resistance to the low $M_{\mathrm{r}}$ fungal epipolythiodiketopiperazine toxin, gliotoxin, varied threefold between the phytopathogens Pythium ultimum and Rhizoctonia solani. Uptake of radiolabelled gliotoxin was rapid and concentration dependent. Uptake by $P$. ultimum was largely complete within $1 \mathrm{~min}$ while the rate of uptake peaked within $10 \mathrm{~min}$ for $R$. solani (anastomosis groups 2-2 and 4). Uptake of gliotoxin by P. ultimum was twice that shown by the more resistant $R$. solani. A deep rough mutant of Salmonella typhimurium, deficient in outer-membrane polysaccharide synthesis, was hypersensitive to gliotoxin, indicating that diffusion barriers play a role in relative sensitivity to gliotoxin. Fungal glutathione levels (reduced and oxidized) did not differ appreciably before or after gliotoxin exposure, indicating that this cytoplasm-based detoxification mechanism was not important in the relative fungal sensitivity to gliotoxin. Binding of the radiolabelled thiol reagents $N$-ethylmaleimide (NEM) and iodoacetic acid to fungal thiol groups was inhibited by gliotoxin. Conversely, the thiol reagents NEM and $p$ chloromercuribenzoic acid inhibited the uptake of radiolabelled gliotoxin. Uptake of radiolabelled amino acids and glucose was reduced by up to $85 \%$ by gliotoxin $\left(8 \mu \mathrm{g} \mathrm{ml}^{-1}\right)$. It is suggested that the primary mechanism of action of gliotoxin involves selective binding to cytoplasmic membrane thiol groups.
\end{abstract}

\section{INTRODUCTION}

The epithiodiketopiperazine toxins (EPTs), which include the compounds gliotoxin, gliovirin, chetomin and sporidesmin, are produced by numerous fungi (Taylor, 1971; Leigh \& Taylor, 1976; Howell \& Stipanovic, 1983). They are characterized as low- $M_{\mathrm{r}}$, nonpolar molecules with a bridged polysulphide region which confers activity. These compounds possess a broad spectrum of activity including inhibition of fungi, bacteria and viruses. Recent work has shown that gliotoxin also inhibits macrophage adherence (Mullbacher \& Eichner, 1984).

EPT exposure generally results in a cellular stasis as opposed to a lethal response. EPTs have been found to induce mitochondrial swelling (Hadler et al., 1973; Middleton, 1974a), inhibit protein and nucleic acid synthesis (Kerridge, 1958) and also inhibit viral RNA-dependent RNA polymerase (Miller et al., 1968; Ho \& Walters, 1969). EPT activity can be abolished by treatment with reducing agents such as glutathione and dithiothreitol (Cavallito et al., 1946; Trown \& Bilello, 1972; Middleton, 1974b), indicating the importance of the epithio-region in toxicity, and suggesting that inhibitory activity is based upon blocking thiol regions of various intracellular proteins.

Current interest in the biological control of fungal plant pathogens has resulted in the release of EPT-producing fungi for this purpose. An understanding of the specific mechanisms of EPTinduced suppression, and factors regulating EPT sensitivity, is needed to evaluate the potential

\footnotetext{
Abbreviations: EPT, epithiodiketopiperazine toxin; AG, anastomosis group; SLM, synthetic liquid medium; NEM, $N$-ethylmaleimide; PCMBA, $p$-chloromercuribenzoic acid.
} 
effectiveness of EPT-mediated biological control as well as the potential toxicological effects of EPT production.

In this study we report the effect of cellular diffusion barriers on the uptake of gliotoxin and the role of these barriers in the relative sensitivity to gliotoxin. Additionally, we report on the effect of gliotoxin on uptake of radiolabelled substrates and thiol reagents, and the response of intracellular glutathione levels after exposure to gliotoxin, in an attempt to determine the primary site of gliotoxin activity among fungi.

\section{METHODS}

Isolates. Cultures of Rhizoctonia solani Kuhn [isolates 2201 and 4001, anastomosis groups (AGs) 2-2 and 4 respectively] and Pythium ultimum Trow (ATCC 32939) were maintained on a synthetic liquid medium plus agar. Salmonella typhimurium isolates LT2 (wild-type) and 1181 (deep rough Rd2) (Nikaido, 1976) were maintained on nutrient agar. The deep rough isolate is deficient in production of the polysaccharide fraction of the lipopolysaccharide outer membrane, except for the heptose portion.

Cultural conditions. Fungi were grown on synthetic liquid medium (SLM), composition: $\left(\mathrm{g} \mathrm{l}^{-1}\right)$, D-glucose, 6.0; DL-asparagine, $1.5 ; \mathrm{KH}_{2} \mathrm{PO}_{4}, 0.25 ;$ and $\left(\mathrm{ml} \mathrm{1}{ }^{-1}\right), 0.5 \mathrm{M}-\mathrm{CaCl}_{2}, 1 \cdot 0 ; 1 \mathrm{~mm}-\mathrm{ZnCl}_{2}, 1 \cdot 0 ; 1 \mathrm{~mm}-\mathrm{MnCl}_{2} .4 \mathrm{H}_{2} \mathrm{O}, 3 \cdot 0$; $1 \mathrm{mM}-\mathrm{MgCl}_{2} .6 \mathrm{H}_{2} \mathrm{O}, 2 \cdot 0 ; 1 \mathrm{~mm}-\mathrm{FeNaEDTA}, 4 \cdot 0 ; 0 \cdot 1 \mathrm{M}-\mathrm{Na}_{2} \mathrm{~S}_{2} \mathrm{O}_{3} .5 \mathrm{H}_{2} \mathrm{O}, 5 \cdot 0 ; 6 \mathrm{~mm}$-thiamine. $\mathrm{HCl}, 2 \cdot 0$. The medium was buffered with $0 \cdot 1 \mathrm{M}$-sodium phosphate $(\mathrm{pH} \mathrm{5 \cdot 8)}$.

Petri dishes $(100 \times 15 \mathrm{~cm})$ containing $20 \mathrm{ml}$ SLM were inoculated with a small plug of mycelium and incubated for 2-3 d until the mycelial mat diameter was half that of the Petri dish. The fungal mats were then harvested, rinsed with sterile medium and placed in $50 \mathrm{ml}$ fresh medium contained in a Waring blender. The mycelium was blended at low speed for $20 \mathrm{~s}$. Suspensions of hyphal fragments $(0.5 \mathrm{ml}$ for $R$. solani, $0.25 \mathrm{ml}$ for $P$. ultimum $)$ were pipetted into individual Petri dishes containing $20 \mathrm{ml}$ fresh SLM and incubated for $3 \mathrm{~d}$ at $26^{\circ} \mathrm{C}$. Cultures prepared in this manner provided consistent, uniform mycelial mats from which discs could be excised for experiments.

Sensitivity of fungi to gliotoxin. Gliotoxin (gift from S. J. Lucania, E. R. Squibb Co., Princeton, New Jersey, USA) was dissolved in methanol $\left(2 \mathrm{mg} \mathrm{ml}^{-1}\right)$ and added to Petri dishes $(60 \times 15 \mathrm{~cm})$, containing $7 \mathrm{ml} \mathrm{SLM}$, providing concentrations of $1,2,4,8$ and $16 \mu \mathrm{g} \mathrm{ml}^{-1}$. Methanol levels were equalized in all treatments and in the control dishes. Discs ( $3 \mathrm{~mm}$ diameter) were excised from the mycelial mats and transferred to individual Petri dishes. Each experiment, which included four plates for each treatment, was repeated twice. Cultures were incubated for $4 \mathrm{~d}$ in the dark then harvested, and the dry matter determined after drying to constant weight at $85^{\circ} \mathrm{C}$.

Sensitivity of S. typhimurium to gliotoxin. Cultures of strains LT2 and 1181 were grown for $6 \mathrm{~h}\left(37^{\circ} \mathrm{C}, 200\right.$ r.p.m.) in covered test tubes containing Luria broth $\left(\mathrm{g} \mathrm{l}^{-1}\right.$ : tryptone, $10 \cdot 0$; yeast extract, $\left.5 \cdot 0 ; \mathrm{MgSO}_{4} \cdot 7 \mathrm{H}_{2} \mathrm{O}, 0 \cdot 25\right)$. Samples of each culture $\left(6.5 \times 10^{3}\right.$ cells $\left.\mu 1^{-1}\right)(5,10,20,40,80,160$ or $320 \mu \mathrm{l})$ were transferred to sterile tubes and the volume brought to $5 \mathrm{ml}$ with fresh Luria broth. Initial bacterial populations were determined by dilution plating. Gliotoxin was added to a final concentration of $1.5 \mu \mathrm{g} \mathrm{m}^{-1}$ for tubes containing strain 1181 and to $3.0 \mu \mathrm{g} \mathrm{ml}^{-1}$ for tubes containing strain LT2. Cultures were incubated in the dark in an incubator shaker for $24 \mathrm{~h}$ after which time the turbidity was measured $\left(\mathrm{OD}_{600}\right)$ for evidence of bacterial growth.

Production of radiolabelled gliotoxin. Three Petri dishes containing $20 \mathrm{ml}$ gliotoxin medium [composition: $\left(\mathrm{g}^{-1}\right)$, D-glucose, $15 \cdot 0 ;\left(\mathrm{NH}_{4}\right)_{2} \mathrm{SO}_{4}, 2 \cdot 0 ; \mathrm{KH}_{2} \mathrm{PO}_{4}, 0 \cdot 5 ; \mathrm{MgSO}_{4} \cdot 7 \mathrm{H}_{2} \mathrm{O}, 1 \cdot 0 ;$ and $\left(\mathrm{ml} \mathrm{l}^{-1}\right), 1 \mathrm{~mm}$-FeNaEDTA (3.0)] were inoculated with approximately $3 \times 10^{4}$ conidia of Penicillium terlikowskii Zaleski (NRRL 2067). After $48 \mathrm{~h}$ incubation $\left(26^{\circ} \mathrm{C}\right), 2 \mu \mathrm{Ci} \mathrm{L}-\left[\mathrm{U}^{-14} \mathrm{C}\right.$ ]phenylalanine $\left(495 \mathrm{mCi} \mathrm{mmol}^{-1}, 1.83 \mathrm{GBq} \mathrm{mmol}^{-1}\right)$ was added to each culture. After $7 \mathrm{~d}$ the culture filtrates were collected by vacuum filtration through Whatman no. 1 filter paper, and extracted with two $1 / 10$ vols chloroform/water. The chloroform fraction was centrifuged for $5 \mathrm{~min}(17300 \mathrm{~g})$ and collected, then dried in vacuo. The residue was resuspended in $1.0 \mathrm{ml}$ ethanol, then transferred to sheets of silica gel (Eastman Kodak Chromagram uv 254). The sheets were resolved in chloroform/acetone $(7: 3$, v/v) and visualized with short-wave UV. The region co-migrating with a gliotoxin standard was scraped from the sheets and eluted with ethanol. Gliotoxin was quantified by absorbance in ethanol (Beckman double-beam model 35 spectrophotometer) $\left(\lambda_{\max }, 270 \mathrm{~nm} ; \varepsilon=6300 \mathrm{M}^{-1} \mathrm{~cm}^{-1}\right)$. To determine the level of isotope incorporation, samples were added to $10 \mathrm{ml}$ scintillation fluid (ScintiVerse II, Fisher Scientific and counted for $10 \mathrm{~min}$ (Packard Tri-Carb scintillation counter).

Fungal uptake of radiolabelled gliotoxin. Three discs ( $18 \mathrm{~mm}$ diameter) from mycelial mats of each fungus were rinsed with sterile distilled water and transferred to individual Petri dishes $(60 \times 15 \mathrm{~mm})$ containing $7 \mathrm{ml}$ SLM. Two series of experiments were done. In the first radiolabelled gliotoxin was added at concentrations of 2.5 and $5.0 \mu \mathrm{g} \mathrm{ml}^{-1}$ and the discs were removed from the medium after 10,20 and $30 \mathrm{~min}$ incubation. In the second experiment, radiolabelled gliotoxin was added at the single concentration of $3.9 \mu \mathrm{g} \mathrm{ml}^{-1}$ and the discs were removed at time intervals of 1,3 and $5 \mathrm{~min}$. In all cases, the discs were then rinsed with fresh liquid medium containing $5 \mathrm{~mm}$ unlabelled gliotoxin, transferred to vials containing $10 \mathrm{ml}$ scintillation fluid and counted for 
$10 \mathrm{~min}$. Background counts, determined by adding untreated mycelial discs to scintillation fluid, were subtracted from the final values.

Interaction of thiol reagents and gliotoxin. $N$-Ethylmaleimide (NEM) or p-chloromercuribenzoic acid (PCMBA), in methanol, was added to individual Petri dishes $(60 \times 15 \mathrm{~mm})$ containing $7 \mathrm{ml}$ SLM, providing a final concentration of $1 \mathrm{~mm}$. Radiolabelled gliotoxin was then added to each dish providing a final concentration of $3.9 \mu \mathrm{g} \mathrm{ml}^{-1}$. Three discs (18 mm diameter) from mycelial mats of each fungus were rinsed and transferred to individual replicate dishes. After incubation for $10 \mathrm{~min}$ the three discs from each plate were rinsed with fresh liquid medium containing unlabelled gliotoxin, transferred to scintillation vials and counted for $10 \mathrm{~min}$. Background counts determined from discs not treated with gliotoxin, but treated with either NEM or PCMBA, were subtracted as before.

To determine the effect of gliotoxin on the binding of radiolabelled thiol compounds, discs were pre-incubated for $30 \mathrm{~min}$ in medium containing $8 \mu \mathrm{g}$ gliotoxin $\mathrm{ml}^{-1}$, then transferred to fresh medium and incubated for $20 \mathrm{~min}$ with the labelled thiol reagents NEM and iodoacetic acid. [ $\left.\mathrm{H}^{3}\right] \mathrm{NEM}\left(N\right.$-ethyl[2- $\left.{ }^{3} \mathrm{H}\right] \mathrm{maleimide} ; 40 \cdot 5 \mathrm{Ci} \mathrm{mmol}^{-1}$, $\left.1.5 \mathrm{TBq} \mathrm{mmol}^{-1}\right)$ in pentane was diluted with distilled water and the pentane was removed under a stream of nitrogen, then the $\left[{ }^{3} \mathrm{H}\right] \mathrm{NEM}(0 \cdot 25 \mu \mathrm{Ci})$ was added to individual dishes. Iodo $\left[{ }^{3} \mathrm{H}\right]$ acetic acid $\left(1 \cdot 38 \mathrm{Ci} \mathrm{mmol}{ }^{-1}\right.$, $5.1 \mathrm{GBq} \mathrm{mmol}^{-1}$ ) was dissolved in water, passed through a $0.45 \mu \mathrm{m}$ Millipore filter to remove nonspecific binding particles, and added $(0 \cdot 1 \mu \mathrm{Ci})$ to individual Petri dishes.

Effect of gliotoxin on uptake of radiolabelled substrates. Gliotoxin $\left(2 \mathrm{mg} \mathrm{m}^{-1}\right)$ in methanol was added to SLM $\left(7 \mathrm{ml}\right.$ ), providing a concentration of $8.0 \mu \mathrm{g}$ gliotoxin $\mathrm{ml}^{-1}$. For studies of amino acid uptake, asparagine levels were adjusted to $1 \mathrm{mM}$, and for glucose uptake the unlabelled glucose concentration was adjusted to $3 \mathrm{~mm}$. The radiolabelled substrates used were $\mathrm{L}-\left[\mathrm{U}-{ }^{14} \mathrm{C}\right]$ arginine $\left(3.00 \mathrm{Ci} \mathrm{mmol}^{-1}, 11 \cdot 1 \mathrm{GBq} \mathrm{mmol}^{-1}\right), \mathrm{L}-\left[\mathrm{U}-{ }^{14} \mathrm{C}\right]$ phenylalanine $\left(495 \mathrm{mCi} \mathrm{mmol}^{-1}, 1.83 \mathrm{GBq} \mathrm{mmol}^{-1}\right)$ (both at $2 \mu \mathrm{Ci}$ per dish) and $\mathrm{D}-\left[\mathrm{U}^{-14} \mathrm{C}\right] \mathrm{glucose}\left(3 \cdot 30 \mathrm{Ci} \mathrm{mmol}^{-1}\right.$, $12.2 \mathrm{GBq} \mathrm{mmol}^{-1}$; at $5 \mu \mathrm{Ci}$ per dish). Fungal mycelial discs were added as with previous experiments and incubated for $30 \mathrm{~min}$. After rinsing with the appropriate unlabelled substrate the uptake was determined by scintillation counting as before.

Assay of reduced and oxidized glutathione. Gliotoxin was added to Petri dishes $(100 \times 15 \mathrm{~cm})$ containing $20 \mathrm{ml}$ SLM, providing concentrations of $10 \mu \mathrm{g}$ gliotoxin $\mathrm{ml}^{-1}$. Eight discs (18 $\mathrm{mm}$ diameter) were excised from mycelial mats and transferred to each dish. After incubation for $1 \mathrm{~h}$ the discs were removed, rinsed and prepared for determinations of reduced and oxidized glutathione. The experiment contained four replications, repeated once.

To determine reduced glutathione (GSH) levels, four discs from each replicate were placed into individual vials containing $2 \mathrm{ml} 5$-sulphosalicylic acid (5\%,w/v). Samples were homogenized with a Polytron (Brinkmann PCU-2) (max. speed, $1 \mathrm{~min})$, transferred to chilled tubes and pelleted in a refrigerated centrifuge $(27000 \mathrm{~g}, 20 \mathrm{~min})$. Supernatant samples $(0.75 \mathrm{ml})$ were added to $0.75 \mathrm{ml}$ formalin/sodium phosphate $(1: 4, \mathrm{v} / \mathrm{v})$ and maintained at room temperature for $20 \mathrm{~min}$, followed by transfer of $0.4 \mathrm{ml}$ to $1 \mathrm{ml}$ sodium phosphate $(0 \cdot 1 \mathrm{M}, \mathrm{pH} 7 \cdot 2)$ plus $5 \mathrm{mM}$ EDTA. Samples $(0.3 \mathrm{ml})$ were further diluted with $1.7 \mathrm{ml}$ sodium phosphate $(0.1 \mathrm{M}, \mathrm{pH} 9 \cdot 3)$ for a final sample $\mathrm{pH}$ of $8 \cdot 5$.

Oxidized glutathione (GSSG) was determined from the four remaining discs from each replicate by placing the

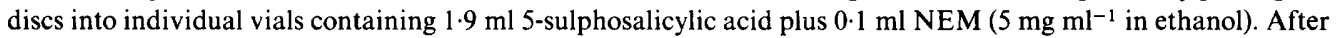
homogenization and centrifugation a $1.5 \mathrm{ml}$ supernatant sample was retained for further use. The sample was neutralized with $2 \mathrm{M}-\mathrm{KOH}$, placed over AG1-X8 formate (Bio-Rad) columns $(0.5 \times 4.5 \mathrm{~cm})$, then washed with $1.5 \mathrm{ml}$ deionized water followed by $1.5 \mathrm{ml}$ sodium formate $(0.1 \mathrm{M})$. GSSG was eluted with $1.5 \mathrm{ml}$ sodium formate $(0.35 \mathrm{M})$ (Beutler \& West, 1977). GSSG samples $(0.75 \mathrm{ml})$ were added to $0.75 \mathrm{ml}$ formalin/sodium phosphate $(1: 4$, $\mathrm{v} / \mathrm{v}$ ) and kept at room temperature for $20 \mathrm{~min}$, after which $0.4 \mathrm{ml}$ was transferred to $1.0 \mathrm{ml}$ sodium hydroxide $(0.1 \mathrm{M})$. Samples $(0.3 \mathrm{ml})$ were further diluted with $1.7 \mathrm{ml} \mathrm{NaOH}(0 \cdot 1 \mathrm{M})$ for a final sample $\mathrm{pH}$ of 11.9 .

To all samples of GSH and GSSG, $0.1 \mathrm{ml} o$-phthalaldehyde $\left(1 \mathrm{mg} \mathrm{ml}^{-1}\right.$ in methanol) was added followed by incubation at room temperature for $15 \mathrm{~min}$ (Mokrasch \& Teschke, 1984). The quantities of GSH and GSSG were determined with a Perkin-Elmer $650-10 \mathrm{~S}$ spectrofluorometer $(350 \mathrm{~nm}$ excitation, $420 \mathrm{~nm}$ emission). Blanks consisted of $0 \cdot 1 \mathrm{ml} o$-phthalaldehyde in either sodium phosphate or sodium hydroxide. Samples of gliotoxin $(5 \mu \mathrm{g})$ were also added to the blanks to determine whether gliotoxin affected emission values. Values were compared to standard curves generated using reagent-grade GSH and GSSG.

Source of chemicals. Radiochemicals were purchased from New England Nuclear except for L-phenylalanine, which was obtained from ICN Radiochemicals. Medium components were purchased from Fisher Scientific. All other compounds were reagent-grade products from Sigma.

\section{RESULTS}

\section{Sensitivity to gliotoxin}

The inhibitory activity of gliotoxin is known to be biomass dependent (Brewer et al., 1966), therefore our values are expressed in terms of biomass. The minimum level of gliotoxin in the 


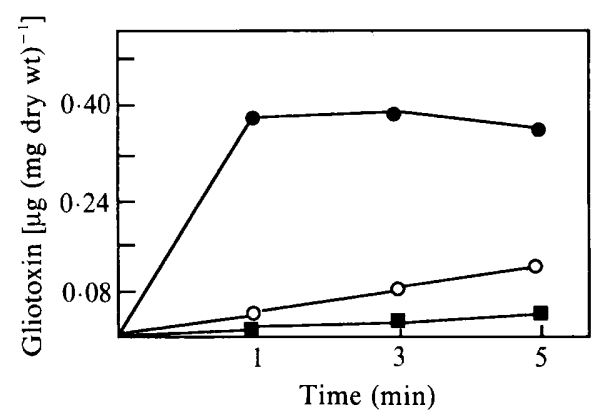

Fig. 1

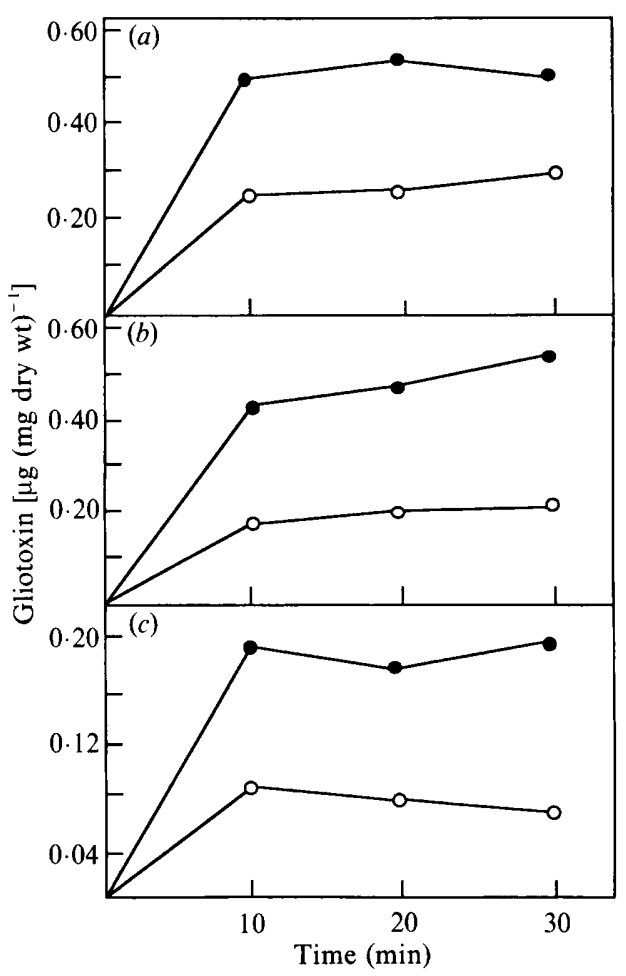

Fig. 2

Fig. 1. Uptake of $\left[{ }^{14} \mathrm{C}\right]$ gliotoxin in medium containing $3.9 \mu \mathrm{g}$ gliotoxin $\mathrm{ml}^{-1}$. Mycelial discs were incubated for 1,3 or $5 \mathrm{~min}$, rinsed with $5 \mathrm{~mm}$ unlabelled gliotoxin and the radioactivity determined by scintillation counting. $-P$. ultimum; $O, R$. solani AG 2-2;,$R$. solani AG 4.

Fig. 2. Uptake of $\left[{ }^{14} \mathrm{C}\right]$ gliotoxin in medium containing $2.5(O)$ and $5.0(\bigcirc) \mu$ g gliotoxin $\mathrm{ml}^{-1}$. Mycelial discs were incubated for 10,20 or $30 \mathrm{~min}$, rinsed with $5 \mathrm{~mm}$ unlabelled gliotoxin and radioactivity determined by scintillation counting. (a) P. ultimum, (b) R. solani AG 2-2, (c) R. solani AG 4.

medium at which growth of the phytopathogenic fungi was completely inhibited was [ $(\mathrm{mg}$ fungal dry wt) ${ }^{-1}$ ]: $P$. ultimum, $9 \cdot 3 \mu \mathrm{g} \mathrm{ml}^{-1} ; R$. solani $2201,17.5 \mu \mathrm{g} \mathrm{ml}^{-1}$, and $R$. solani 4001 , $27.0 \mu \mathrm{g} \mathrm{ml}^{-1}$. The variation is significant when considering the limited level of gliotoxin available in the soil (Wright, 1952). These levels were fungistatic but not fungicidal. Growth of the deep rough mutant of $S$. typhimurium (1181) was prevented at $24 \mathrm{~h}$ when inoculum levels were below $2.0 \times 10^{6}$ cells per $5 \mathrm{ml}$ broth containing $1.5 \mu \mathrm{g}$ gliotoxin $\mathrm{ml}^{-1}$. Growth of the wildtype $S$. typhimurium (LT2) was prevented at $24 \mathrm{~h}$ when inoculum levels were below $1.5 \times 10^{4}$ cells per $5 \mathrm{ml}$ broth containing $3.0 \mu \mathrm{g}$ gliotoxin $\mathrm{ml}^{-1}$. The wild-type was over 13-fold less sensitive even though it was exposed to twice the gliotoxin concentration of the deep rough mutant.

\section{Uptake of radiolabelled gliotoxin}

Radiolabelled gliotoxin was isolated from culture filtrates of $P$. terlikowskii and purified to a specific activity of 1464 d.p.m. ( $\mu$ g gliotoxin $)^{-1}$. Incorporation was approximately $2 \cdot 1 \%$. When the radiolabelled gliotoxin was added to SLM containing the test fungi, its uptake was rapid and concentration dependent (Figs 1 and 2). The rates varied considerably between the fungi. Uptake by $P$. ultimum was largely completed in less than $1 \mathrm{~min}$, whereas the isolates of $R$. solani took at least $10 \mathrm{~min}$ to approach the maximum binding. The amount of uptake also differed, with $P$. ultimum and $R$. solani 2201 taking up over twice the amount of gliotoxin than was taken up by $R$. solani 4001 . Unlabelled gliotoxin interfered with uptake of radiolabelled gliotoxin, indicating that they had the same binding site. 
Table 1. Effect of thiol reagents on uptake of $\left[{ }^{14} \mathrm{C}\right]$ gliotoxin

Mycelial discs were incubated for $10 \mathrm{~min}$ in medium containing $\left[{ }^{14} \mathrm{C}\right]$ gliotoxin $\left(3.9 \mu \mathrm{g} \mathrm{ml}^{-1}\right)$ alone or in combination with $1 \mathrm{mM}-\mathrm{NEM}$ or PCMBA. Values represent $\mu \mathrm{g}$ gliotoxin (mg mycelial dry wt) ${ }^{-1}$ and are based upon three replicates. Relative values were consistent between experiments.

\begin{tabular}{lccc}
\multicolumn{1}{c}{ Organism } & Control & NEM & PCMBA \\
$P$. ultimum & 0.400 & $0 \cdot 136$ & 0.380 \\
$R$. solani 2201 & 0.430 & 0.168 & 0.375 \\
$R$. solani 4001 & $0 \cdot 120$ & 0.022 & $0 \cdot 120$
\end{tabular}

Table 2. Effect of gliotoxin on uptake of radiolabelled thiol reagents

Mycelial discs were incubated for $30 \mathrm{~min}$ with gliotoxin $\left(8 \mu \mathrm{g} \mathrm{ml}^{-1}\right)$, then incubated for $20 \mathrm{~min}$ with the radiolabelled thiol reagents. Values are expressed as c.p.m. (mg mycelial dry wt) ${ }^{-1}$ and are the means of three replicates; SEM values are given in parentheses. Relative values were consistent between experiments.

\begin{tabular}{lrrrrr}
\multicolumn{1}{c}{ Organism } & $\overbrace{\text { Control }}^{\text {Iodo }\left[{ }^{3} \mathrm{H}\right] \text { acetic acid }}$ & & Treated & $\overbrace{\text { Control }}$ & Treated \\
$P$. ultimum & $2155(23)$ & $1218(102)$ & $2607(264)$ & $1877(224)$ \\
R. solani 2201 & $137(10)$ & $133(16)$ & $10351(596)$ & $9549(377)$ \\
$R$. solani 4001 & $288(20)$ & $190(38)$ & $6497(214)$ & $4966(210)$
\end{tabular}

Table 3. Effect of gliotoxin on uptake of radiolabelled precursors

Mycelial discs were incubated for $30 \mathrm{~min}$ in liquid medium containing radiolabelled compounds and $8 \mu \mathrm{g}$ gliotoxin $\mathrm{ml}^{-1}$. Values are expressed as c.p.m. (mg mycelial dry wt) ${ }^{-1}$ and are the means of three replicates; SEM values are given in parentheses.

\begin{tabular}{|c|c|c|c|c|c|c|}
\hline \multirow[b]{2}{*}{ Organism } & \multicolumn{2}{|c|}{ L-Arginine } & \multicolumn{2}{|c|}{ L-Phenylalanine } & \multicolumn{2}{|c|}{ D-Glucose } \\
\hline & Control & Gliotoxin & Control & Gliotoxin & Control & Gliotoxin \\
\hline P. ultimum & $1556 \quad(70)$ & $237 \quad(7)$ & $3808 \quad(29)$ & $1527(120)$ & $2604(305)$ & $1876(200)$ \\
\hline R. solani 2201 & $1737(222)$ & $393(23)$ & $7389(628)$ & $5202(453)$ & $4914(314)$ & $3033(97)$ \\
\hline R. solani 4001 & $160 \quad(36)$ & $123(1)$ & $2318(466)$ & $758(175)$ & $2856(259)$ & $2399(361)$ \\
\hline
\end{tabular}

\section{Interaction between thiol reagents and gliotoxin}

The organisms varied in their uptake of radiolabelled gliotoxin in the presence of thiol reagents (Table 1). The permeant NEM reduced gliotoxin uptake by $66 \%, 61 \%$ and $82 \%$, respectively, for $P$. ultimum, $R$. solani 2201 and $R$. solani 4001 . The nonpermeant PCMBA reduced gliotoxin uptake by $5 \%, 30 \%$ and $0 \%$, respectively, for the same fungi at the end of a $10 \mathrm{~min}$ incubation. The two compounds differ in reactivity: NEM binds to internal and external thiol groups, while PCMBA generally reacts only with external thiol regions. That they both inhibit gliotoxin uptake indicates that gliotoxin is binding to various thiol regions accessible to both NEM and PCMBA. Preliminary studies showed that gliovirin, sodium nitrite and various dipeptides did not interfere with gliotoxin uptake, indicating preferential binding sites between each of the tested compounds. Gliotoxin was able to reduce the binding of radiolabelled thiol reagents (Table 2). Pre-incubation with gliotoxin resulted in $28 \%, 8 \%$ and $24 \%$ reductions in binding of $\left[{ }^{3} \mathrm{H}\right]$ NEM by $P$. ultimum, $R$. solani 2201 and $R$. solani 4001 . Gliotoxin reduced iodo $\left[{ }^{3} \mathrm{H}\right]$ acetic acid binding by $43 \%$ for $P$. ultimum. Iodo $\left[{ }^{3} \mathrm{H}\right]$ acetic acid binding was very low for the other fungi even in the absence of gliotoxin.

\section{Effect of gliotoxin on uptake of radiolabelled substrates}

The simultaneous incubation of gliotoxin with radiolabelled substrates resulted in a marked decline in their uptake (Table 3). Uptake of L-arginine was reduced by $85 \%$ for $P$. ultimum and 
Table 4. Effect of gliotoxin on intracellular levels of fungal glutathione

Mycelial discs were incubated in glucose/asparagine liquid medium with $10 \mu \mathrm{g}$ gliotoxin $\mathrm{ml}^{-1}$ for $1 \mathrm{~h}$. Glutathione was assayed spectrophotometrically with $o$-phthalaldehyde as detailed in Methods. Values are expressed as pmol (mg mycelial dry $\left.\mathrm{wt}^{-1}\right)^{-1}$ and are the means of four replicates; SEM values are given in parentheses.

\begin{tabular}{lccrrrr}
\multicolumn{1}{c}{ Organism } & $\overbrace{\text { Control }}^{\text {GSH }}$ & \multicolumn{2}{c}{ Treated } & & Control & Treated \\
$P$. ultimum & $8450(250)$ & $7800(300)$ & & $102(2)$ & $65(30)$ \\
R. solani 2201 & $7300(100)$ & $6850(50)$ & $27(3)$ & $19(1)$ \\
R. solani 4001 & $7750(550)$ & $6850(1550)$ & $39(5)$ & $17(3)$
\end{tabular}

by $77 \%$ for $R$. solani 2201 . Uptake of L-phenylalanine was reduced by $60 \%, 30 \%$ and $67 \%$, respectively, for $P$. ultimum, $R$. solani 2201 and $R$. solani 4001 . Uptake of D-glucose was reduced by $28 \%, 38 \%$ and $16 \%$ for the same fungi.

\section{Effects of gliotoxin on glutathione levels}

Initial glutathione levels did not correlate with the observed variations in fungal sensitivity to gliotoxin. There were also no appreciable changes in the levels of reduced glutathione (GSH) after exposure of mycelia to gliotoxin (Table 4). Interactions between GSH and gliotoxin can occur during the extraction process and could account in part for the slight decline in GSH levels. Levels of oxidized glutathione (GSSG) declined slightly. This may represent GSSG reductase activity, but the contribution to the GSH pool would be minimal given the magnitude of GSSG depletion. This evidence suggests either that gliotoxin does not enter the cytoplasm or that glutathione does not react with gliotoxin in the cytoplasm. In either case glutathione would not play a role as a detoxicant for gliotoxin resistance.

\section{DISCUSSION}

The variation in the uptake of gliotoxin by the fungi studied here correlates in part with their observed sensitivity to gliotoxin. The uptake is concentration dependent and levels off within $10 \mathrm{~min}$. The kinetics imply a passive, adsorptive process. The same observation has been made for the uptake of sporidesmin by rumen protozoa (Shaw \& Wright, 1972). The role of diffusion in uptake of gliotoxin is also seen with $S$. typhimurium mutants, where defects in production of the polysaccharide region of the outer membrane (Nikaido \& Vaara, 1985) result in large increases in sensitivity to gliotoxin. The sensitivity to gliotoxin of a Gram-negative bacterium, deficient in production of outer membrane polysaccharide, suggests that the relative gliotoxin sensitivity among micro-organisms may be a reflection of the ability of gliotoxin to reach sensitive cellular sites. It also indicates that there are cellular sites which are sensitive to gliotoxin among Gramnegative bacteria.

Moderate levels of resistance to gliotoxin were previously obtained for Staphylococcus aureus (Klimek et al., 1948) and Bacillus subtilis (Brewer et al., 1967) after repeated subculturing (30-80 transfers) on gliotoxin-amended medium. The resistance was lost after culturing the bacteria on gliotoxin-free medium. It is known that the cell-wall hydrophobicity changes after repeated subculturing and, given the selection pressure of a hydrophobic antibiotic, the cells might be selected for reduced permeation of the antibiotic, which could be accomplished through reduced cell-wall hydrophobicity.

The structure and composition of fungal cell walls is not as well characterized as the outer membrane of Gram-negative bacteria. It is likely that adaptations in structure and composition have been selected for based upon the particular environment in which the organism exists (Cook \& Baker, 1983). P. ultimum is a rapid growing primary colonizer of fresh organic matter. Its hyphal walls would be expected to be quite permeable to allow for rapid diffusion of low- $M_{\mathrm{r}}$ nutrients to support rapid growth. It is, however, highly susceptible to antibiosis, with survival 
between periods of fresh organic matter occurring through production of sporangia and oospores (Stanghellini \& Hancock, 1971). R. solani colonizes organic matter later than $P$. ultimum; it grows more slowly but has a higher competitive saprophytic activity (Papavizas, 1964). The saprophytic activity varies between AGs of $R$. solani. $R$. solani AG 2-2 has the more limited saprophytic capability. It produces abundant sclerotia and generally attacks plants aerially or near the soil surface, thus it has limited exposure to antibiotic-producing organisms. $R$. solani AG 4 has stronger saprophytic abilities than AG 2-2 and is more resistant to inhibitory compounds. $R$. solani apparently employs its cell wall as a diffusion barrier which allows for growth under harsher environmental conditions; this is similar to enteric bacteria which employ their outer membrane as a permeability barrier.

Biological control of phytopathogenic fungi may be limited by the architecture and chemical composition of cell walls of the target organism. We have shown that the walls can mediate the diffusion of hydrophobic antibiotics such as gliotoxin. One means of overcoming this barrier would be mycoparasitism, where degradation of the cell wall could allow for passage of the antibiotic. This would not be effective in systems where rapid pathogen control is desired, such as protection of seeds and seedlings; however, it may play a role in the long-term reduction of pathogen inoculum.

The blocking of membrane thiol groups by gliotoxin evidently accounts for its broadspectrum activity. It provides a highly effective means for producer organisms to compete with and/or displace other organisms. This could explain why a number of soil-borne fungi have the ability to produce gliotoxin and related compounds (Taylor, 1971). The broad-spectrum, nonspecific, moderately toxic activity of gliotoxin suggests that resistance will not readily arise.

Under the nutrient-limited conditions prevalent in many soils it is expected that microorganisms depend on high permease activity. Many permeases are sensitive to thiol reagents (Nelson et al., 1975). Also, fungal propagules often depend upon exogenous nutrients to induce germination. Interference with these nutrient uptake mechanisms could rapidly lead to nutrientdependent fungistasis. Our studies were done at gliotoxin concentrations similar to those levels detected in the soil (Wright, 1952), therefore it is likely that our results reflect events which could actually occur in the soil. The nutrient limiting activity of gliotoxin suggests that its efficacy will be reduced in soils with high levels of organic matter and on root surfaces, where nutrients would be less limiting.

The variation in sensitivity to EPTs among micro-organisms may also be due to the susceptibility of target sites on their cell membranes. The membrane transport capabilities have been shown to differ between isolates of $R$. solani (Lin \& Gottlieb, 1974). The variation in competition between thiol reagents and gliotoxin, depending on the test fungus, suggests that the availability of the target sites differs between organisms. The same has been observed for other membrane thiol binding compounds (Cunningham et al., 1979; Morris et al., 1984). Previous work on the mode of action of EPTs did not study the effects on membrane thiol groups. Kerridge (1958) found that gliotoxin $\left(30 \mu \mathrm{g} \mathrm{ml}^{-1}\right)$ prevented incorporation of glycine into proteins and nucleic acids but did not determine if the isotope-labelled glycine was initially taken up by the test organism, Saccharomyces carlsbergensis, after exposure to gliotoxin. The secondary effects of membrane thiol group inhibition can be misinterpreted as the primary cellular response. For example, cytochalasin A or sodium nitrite exposure results in multiple alterations of cellular physiology but their primary mechanism of action is binding to membrane thiol groups (Cunningham et al., 1979; Morris et al., 1984).

The suggestion that swelling of isolated, gliotoxin-treated mitochondria was due to a reaction with thiol groups of mitochondrial membrane proteins (Hadler et al., 1973; Middleton, 1974b) was probably accurate; however, this does not appear to be the initial site of EPT activity. Reaction with mitochondria may not even occur in vivo except possibly at high EPT levels, as there is no evidence that EPTs at low dosages enter the cytoplasm at significant concentrations. In our experiments intracellular glutathione status did not change in the presence of gliotoxin, which provides support for the idea that gliotoxin does not initially enter the cytoplasm. Glutathione levels were assayed after $1 \mathrm{~h}$ of exposure to gliotoxin while the majority of gliotoxin uptake is complete within $10 \mathrm{~min}$. Gliotoxin and glutathione react spontaneously, without the 
need for glutathione transferase activity, so interference with this enzyme would not account for a lack of glutathione depletion. Another EPT, sporidesmin, was also found not to accumulate in the cytoplasm of protists (Shaw \& Wright, 1972).

It is possible that reactions with membrane thiol groups can lead to increased membrane permeability by affecting the orientation of the membrane proteins. In this study we did not determine whether leakage occurred. We would expect, however, based upon the fact that glutathione levels were not significantly altered, that membrane leakage was not occurring. Also, Mullbacher et al. (1985) found that inhibition of macrophage adherence, after treatment with gliotoxin, was not accompanied by alteration in the permeability of the macrophage membrane. Our data, showing interference with membrane thiol regions, suggest that the same mechanism may be involved in the inhibition of macrophage adherence. Cellular adhesion can be inhibited by thiol reagents (Grinnell \& Srere, 1971).

Evidence for in situ production of gliotoxin in lung tissue infected with Aspergillus fumigatus has not been shown. If gliotoxin is in fact produced in situ, then it would be interesting to determine its effect on another lung-infecting fungus, Histoplasma capsulatum. The temperaturedependent conversion of $H$. capsulatum from a mycelial stage to the infective yeast stage can be irreversibly blocked by thiol-reactive compounds (Medoff et al., 1986). It would also be interesting to determine whether gliotoxin-mediated plant disease suppression is, in part, due to plant phytoalexin induction, as phytoalexin production can be induced by compounds reacting with membrane thiol groups (Gustine, 1987).

The information provided by this study should prove useful in understanding the mechanisms mediating the control of plant disease through introduction of EPT-producing organisms to the soil. Additionally, this information should prove valuable in toxicological studies which are required before registration of EPT-producing organisms as commercial biological control agents.

\section{REFERENCES}

Beutler, E. \& WeSt, C. (1977). Comment concerning a fluorimetric assay for glutathione. Analytical Biochemistry 81, 458-460.

Brewer, D., Hannah, D. E. \& Taylor, A. (1966). The biological properties of 3,6-epidithiadiketopiperazines. Inhibition of growth of Bacillus subtilis by gliotoxins, sporidesmins, and chetomin. Canadian Journal of Microbiology 12, 1187-1195.

Brewer, D., Hannah, D. E., Rahman, R. \& Taylor, A. (1967). The growth of Bacillus subtilis in media containing chetomin, sporidesmin, and gliotoxin. Canadian Journal of Microbiology 13, 14511460.

Cavallito, C. J., Bailey, J. H. \& Warner, W. F. (1946). The reversible inactivation of gliotoxin by thiols. Journal of the American Chemical Society 68 , 715-716.

COOK, R. J. \& BAKER, K. F. (1983). The Nature and Practice of Biological Control of Plant Pathogens. St. Paul, Minnesota: American Phytopathological Society.

Cunningham, D., Flashner, M. \& Tanenbaum, S. W. (1979). Evidence for selective sulfhydryl reactivity in cytochalasin A-mediated bacterial inhibition. Biochemical and Biophysical Research Communications 86, 173-179.

GrinNell, F. \& SRERE, P. A. (1971). Inhibition of cellular adhesiveness by sulfhydryl blocking agents. Journal of Cell Physiology 78, 153-158.

Gustine, D. L. (1987). Induction of medicarpin biosynthesis in Ladino clover callus by $p$-chloromercuribenzoic acid is reversed by dithiothreitol. Plant Physiology 84, 3-6.
Hadler, H. I., Hadler, M. R. \& Daniel, B. G. (1973). The direct in vitro action of gliotoxin on rat liver mitochondria. Journal of Antibiotics 36, 36-43.

Ho, P. P. K. \& Walters, C. P. (1969). Specific inhibition of influenza virus-induced ribonucleic acid polymerase by gliotoxin. Antimicrobial Agents and Chemotherapy 1968, 68-71.

Howell, C. R. \& Stipanovic, R. D. (1983). Gliovirin, a new antibiotic from Gliocladium virens, and its role in the biological control of Pythium ultimum. Canadian Journal of Microbiology 29, 321-324.

KERRIDGE, D. (1958). The effect of actidione and other antifungal agents on nucleic acid and protein synthesis in Saccharomyces carlsbergensis. Journal of General Microbiology 19, 497-506.

Klimek, J. W., Cavallito, C. J. \& Bailey, J. H. (1948). Induced resistance of Staphylococcus aureus to various antibiotics. Journal of Bacteriology 55, 139-145.

Leigh, C. \& TAYLOR, A. (1976). The chemistry of the epipolythiopiperazine-3,6-diones. In Mycotoxins and Other Fungal Related Food Problems, pp. 228-275. Edited by J. V. Rodricks. Washington, DC: American Chemical Society.

LIN, F. \& GoTTLIEB, D. (1974). Cellular basis of growth rate differences in isolates of Rhizoctonia solani: Metabolic processes and growth rates. Phytopatho$\log y$ 64, 1220-1228.

Medoff, G., Sacco, M., Maresca, B., Schlessinger, D., Painter, A., Kobayashi, G. S. \& Carratu, L. (1986). Irreversible block of the mycelial-to-yeast phase transition of Histoplasma capsulatum. Science 231, 476-479. 
Middleton, M. C. (1974a). Effects of the mycotoxin sporidesmin on swelling and respiration of liver mitochondria. Biochemical Pharmacology 23, 801810.

Middleton, M. C. $(1974 b)$. The involvement of the disulfide group of sporidesmin in the action of the toxin on swelling and respiration of liver mitochondria. Biochemical Pharmacology 23, 811-820.

Miller, P. A., Milstrey, K. P. \& Trown, P. W (1968). Specific inhibition of viral ribonucleic acid replication by gliotoxin. Science 159, 431-432.

MoKRASCH, L. C. \& TESCHKE, E. J. (1984). Glutathione content of cultured cells and rodent brain regions : a specific fluorimetric assay. Analytical Biochemistry 140, 506-509.

MorRis, S. L., Walsh, R. C. \& Hansen, J. N. (1984). Identification and characterization of some bacterial membrane sulfhydryl groups which are targets of bacteriostatic and antibiotic action. Journal of Biological Chemistry 259, 13590-13594.

MullbaCHER, A. \& EICHNER, R. D. (1984). Immunosupression in vitro by a metabolite of a human pathogenic fungus. Proceedings of the National Academy of Sciences of the United States of America 81, 3835-3837.

Mullbacher, A., Waring, P. \& Eichner, R. D. (1985). Identification of an agent in cultures of Aspergillus fumigatus displaying anti-phagocytic and immunomodulating activity in vitro. Journal of General Microbiology 131, 1251-1258.

Nelson, S. O., Glover, G. I. \& Magill, C. W. (1975).
The essentiality of sulfhydryl groups to transport in Neurospora crassa. Archives of Biochemistry and Biophysics 168, 483-489.

NiKaIDo, H. (1976). Outer membrane of Salmonella typhimurium: transmembrane diffusion of some hydrophobic substances. Biochimica et biophysica acta 433, 118-132.

Nikaido, H. \& VAARA, M. (1985). Molecular basis of outer membrane permeability. Microbiological $R e$ views 49, 1-32.

Papavizas, G. C. (1964). Survival of single-basidiospore isolates of Rhizoctonia praticola and Rhizoctonia solani. Canadian Journal of Microbiology 10, 739-746.

Shaw, B. A. \& Wright, D. E. (1972). The action of sporidesmin on rumen protozoa. New Zealand Journal of Agricultural Research 15, 508-511.

Stanghellini, M. E. \& Hancock, J. G. (1971). The sporangium of Pythium ultimum as a survival structure in soil. Phytopathology 61, 157-164.

TAYLOR, A. (1971). The toxicology of sporidesmins and other epipolythiadioxopiperazines. In Microbial Toxins, vol. 7, pp. 37-376. Edited by S. Kadis, A. Ciegler \& S. J. Ajl. New York: Academic Press.

Trown, P. W. \& Bilello, J. A. (1972). Mechanisms of action of gliotoxin: elimination of activity by sulfhydryl compounds. Antimicrobial Agents and Chemotherapy 2, 261-266.

WRIGHT, J. M. (1952). Production of gliotoxin in unsterilized soil. Nature, London 170, 673-674. 